Int. J. Electrochem. Sci., 11 (2016) $4219-4230$

International Journal of

ELECTROCHEMICAL

SCIENCE

www.electrochemsci.org

\title{
Test of Different Anode Electrocatalysts for Direct Glucose Anion Exchange Membrane Fuel Cell
}

\author{
Spets Jukka-Pekka ${ }^{1, *}$, Kanninen Petri ${ }^{2}$, Kallio Tanja ${ }^{2}$, Selkäinaho Jorma ${ }^{3}$, Kiros Yohannes ${ }^{4}$, \\ Saari Kari ${ }^{l}$, Larmi Martti ${ }^{1}$ \\ ${ }^{1}$ Dept. Mechanical Engineering, School of Engineering, Aalto University, Espoo, P.O. Box 14400, FI- \\ 00076 Aalto, Finland \\ ${ }^{2}$ Dept. Chemistry, School of Chemical Technology, Aalto University, Espoo, P.O. Box 16000, FI- \\ 00076 Aalto, Finland \\ ${ }^{3}$ Dept.Electrical Engineering and Automation, School of Electrical Engineering, Aalto University, \\ Espoo, P.O. Box 15500, FI-00076 Aalto, Finland \\ ${ }^{4}$ Dept. Chemical Engineering and Technology, KTH - Royal Institute of Technology, SE-100 44 \\ Stockholm, Sweden \\ *E-mail: jukka-pekka.spets@aalto.fi
}

doi: $10.20964 / 2016.06 .25$

Received: 3 March 2016 / Accepted: 23 March 2016 / Published: 4 May 2016

Direct glucose anion exchange membrane fuel cell (AEMFC) with near-neutral-state electrolyte of $0.1 \mathrm{M}\left[\mathrm{PO}_{4}\right]$ tot was studied with five different anode electrocatalysts (Pt, PtRu, PtNi, $\mathrm{Au}, \mathrm{PdAu}$ ) at a temperature of $37{ }^{\circ} \mathrm{C}$ and at a glucose concentration of $0.1 \mathrm{M}$. The cathode catalyst in each test was $\mathrm{Pt}$ supported on carbon $(60 \mathrm{wt} . \%)$. Four anode electrocatalysts (supported on carbon) had a total metal content of $40 \mathrm{wt} . \%$ while the fifth anode material of PtRu had a higher content of $60 \mathrm{wt} . \%$. Moreover, in order to show the influence of the metallic content on the fuel cell performance, anode catalysts with 60 wt.\% (Pt) and 10wt.\% (PtNi) were tested. The operation of the AEMFC was controlled by means of an in-house-made electronic load with PI-controller (i.e. a feedback controller that has proportional and integral action on control error signal) either at constant current (CC) or at constant voltage (CV). The primary objective was to characterize the Coulombic efficiency (CE) based on the exchange of two electrons and compare the specific energy $\left(\mathrm{Wh} \mathrm{kg}^{-1}\right)$ for the direct glucose AEMFC related to the different electrode combinations and electrocatalysts. As a result of these screening tests, two most efficient anode electrodes with Pt and PtNi were selected to be used for further AEMFC studies.

Keywords: glucose, anode electrocatalysts, anion exchange membrane fuel cell, near-neutral-state electrolyte 
(C) 2016 The Authors. Published by ESG (www.electrochemsci.org). This article is an open access article distributed under the terms and conditions of the Creative Commons Attribution license (http://creativecommons.org/licenses/by/4.0/). 